TITLE:

\title{
Emission of Particulate Matter 2.5 (PM2.5) from Sewage Sludge Incinerators in Japan
}

\section{AUTHOR(S):}

Shiota, Kenji; Takaoka, Masaki; Yamaguchi, Shuji; Oshita, Kazuyuki

\section{CITATION:}

Shiota, Kenji ... [et al]. Emission of Particulate Matter 2.5 (PM2.5) from Sewage Sludge Incinerators in Japan. Drying Technology 2015, 33(11): 1286-1294

\section{ISSUE DATE:}

2015-04-15

URL:

http://hdl.handle.net/2433/201955

\section{RIGHT:}

This is an Accepted Manuscript of an article published by Taylor \& Francis in 'Drying Technology: An International Journal (2015)', available online: http://www.tandfonline.com/10.1080/07373937.2015.1026977.; The full-text file will be made open to the public on 15 April 2016 in accordance with publisher's 'Terms and Conditions for Self-Archiving'.; This is not the published version. Please cite only the published version.; この論文は出版社版でありません。引用の際には 出版社版をご確認ご利用ください。 
Article Title: Emission of particulate matter 2.5 (PM2.5) from sewage sludge incinerators in Japan

Journal name: Drying Technology

Corresponding author: Kenji Shiota

Kyoto University, Department of Environmental Eng., Graduate School of Engineering, Nishikyo-ku, Kyoto, 615-8540 Japan

E-mail: shiota.kenji.4x@kyoto-u.ac.jp, Tel: +81-75-383-7550, Fax: +81-75-383-3338

Co-authors: Masaki Takaoka ${ }^{1,2}$, E-mail: takaoka.masaki.4w@kyoto-u.ac.jp

Shuji Yamaguchi², E-mail: yamaguchi@epsehost.env.kyoto-u.ac.jp

Kazuyuki Oshita ${ }^{1,2}$, E-mail: oshita.kazuyuki.6e@kyoto-u.ac.jp

1 Kyoto University, Department of Global Ecology, Graduate School of Global Environmental Studies

2 Kyoto University, Department of Environmental Eng., Graduate School of Engineering, Nishikyo-ku, Kyoto, 615-8540 Japan

\section{ACKNOWLEDGEMENT}

This study was supported by the research grants from Osaka Bay Regional Offshore Environmental Improvement Center and The Environment Research and Technology Development Fund (220002). We greatly appreciate Shimadzu Techno-Research, INC. and relevant local governments for help with sampling at SSIs. 


\section{ABSTRACT}

Because fine particulate matter $\leq 2.5 \mu \mathrm{m}$ in diameter (PM2.5) causes health problems, PM2.5 emissions are of concern. However, little research on stationary sources has been conducted. To determine the concentration and filtration behaviour of PM2.5, dust was collected from five fluid bed sewage sludge incinerators (SSIs) sorted by particle size using cascade impactors. The average PM2.5 concentration was $0.00014-4.8 \mathrm{mg} / \mathrm{Nm}^{3}$. The total estimated amount of PM2.5 emissions from the SSIs for all plants in Japan was 0.96-8.9 tons/year. Since the SSIs with dry Electrostatic Precipitators (EP) contributed 75-99\% of the total emissions, replacing dry EPs with Bag Filters would significantly reduce the PM2.5 emissions from SSI.

\section{KEYWORDS}

PM2.5, sewage sludge incinerator, bag filter, electrostatic precipitator, emission

\section{INTRODUCTION}

In recent years, fine particulate matter $\leq 2.5 \mu \mathrm{m}$ in diameter (PM2.5) has attracted increasing attention because of its health risk and the high PM2.5 concentrations in some rapidly industrialising areas. ${ }^{[1,2]}$ Epidemiological studies have demonstrated a relationship between mortality and long-term exposure to PM2.5 in ambient air. ${ }^{[3,4]}$ Many international organisations have assessed the health risks of exposure to PM, and the European Union, United States, and World Health Organisation (WHO) established quality standards for ambient air in $2005^{[5]}$ and 2006. ${ }^{[6,7]}$ In Japan, PM2.5 was added to the Japanese environmental standards in September 2009. These hold that the annual average PM2.5 concentration should be less than $15 \mu \mathrm{g} / \mathrm{m}^{3}$ and the daily average less than $35 \mu \mathrm{g} / \mathrm{m}^{3}$.

Recently, the multinational European EBoDE-project estimated that particulate matter (PM) was associated with the highest disease burden (6 000-10 000 DALYs per million people), followed in order by second-hand smoke, noise, and radon. Disability-adjusted life years (DALYs) are a summary measure of population health combining mortality and morbidity. ${ }^{[8]}$ The International Agency for Research on Cancer (IARC) also classified PM as carcinogenic to humans. ${ }^{[9]}$

As primary particles, sources of PM2.5 include both anthropogenic sources such as combustion plants and vehicle emissions, and natural sources such as yellow sand, etc. It is also notable that secondary particles produced from gases affect atmospheric PM2.5 levels. However, few studies have determined PM2.5 levels from sources other than ambient air and most of the studies of PM2.5 sources have examined mobile sources, with few direct measurements of PM2.5 in flue gases. ${ }^{[10-12]}$ To prevent PM2.5 emissions, it is necessary to examine the present state of PM2.5 emissions from stationary sources. We have investigated some stationary sources of PM2.5 in recent years. ${ }^{[13,14]}$

In Japan, sewage sludge represents one of the largest sources of industrial waste, with amounts produced increasing with the increase in the population using sewage treatment systems. The overall treatment system produces $\sim 2.2$ million tons of dry sewage sludge (Dried Sludge; DS) annually. ${ }^{[15]}$ Incineration techniques are widely used for disposal of sewage sludge, this reduces the volume of sludge and transforms waste into solid incineration ash, which facilitates easy waste handling. Due to the small land area available 
in Japan, it is difficult to dispose of large quantities of sludge without intermediate treatment. Therefore, $\sim 68 \%$ (1.5 million tons-DS) of sludge was incinerated in sewage sludge incinerators (SSIs) in 2008. ${ }^{[15]}$ Incineration emits toxic substances such as dioxin ${ }^{[16]}$ and mercury ${ }^{[17]}$ as well as large quantities of dust and PM2.5. However, no recent study has measured PM2.5 emissions from SSIs.

This study focused on the emission of PM2.5 from SSIs. We collected dust samples from five SSI plants according to particle size using an Andersen stack sampler to evaluate the concentration, removal ability, emission factor, and emission mass of PM2.5 from SSIs. This paper assumes that PM2.5 from SSI is the primary particle in the SSI flue gases.

\section{MATERIALS AND METHODS}

\section{Sewage Sludge Incineration plants}

Dust sampling was carried out at five continuous fluidized-bed-type SSI plants with different dust collectors. Two of the five plants had dry electrostatic precipitators (EP; plants EP1 and EP2), and the remaining three plants had both EP and wet EP (plant EP+WEP), bag filter (BF; plant BF), and ceramic filter (CF; plant CF), respectively. Generally, EP removes dust from flue gases using an electrostatic force. The removal efficiency for $10 \mu \mathrm{m}$ particles is more than $99.5 \%$. WEP is an EP that includes cleaning equipment that rinses gases with water, which results in removal efficiency better than that provided by EP alone. Fabric filters such as BF and CF remove dust from flue gases by filtration. This type of filter has much higher dust removal efficiency than EP has, particularly for fine particles. The temperature resistance of CF is better than that of BF due to the materials used in their manufacture. ${ }^{[18]}$ All of the incinerators had fluidised beds, a popular type of incinerator for sewage sludge in Japan. ${ }^{[19]}$ The fluidized beds are heated to an annual average temperature between 820 and $854^{\circ} \mathrm{C}$, and sewage sludge burns continuously at a rate that depends on the incineration capacity of each plant. The sewage sludge in cake form is partially dewatered by a dewatering system such as a belt filter press (plant EP1, EP2, and EP+WEP), centrifuge (plant BF), screw press and indirect heating (plant CF). The sludge cakes contained 74.6 to 84\% moisture when wet and 70.6 to $86.0 \%$ organic matter content when dried; the composition of the sludge tended to be similar to each other and in good agreement with previous reports. ${ }^{[20-24]}$ Among these plants, operational conditions are similar with respect to the incinerator, coagulant, combustion temperature, and organic content in sludge cake. Figure 1 and Table 1 show a summary of the plant flow and an outline of technical data, respectively, for each SSI plant.

FIG. 1. Plant flow and sampling points

TABLE 1 Technical data for five SSI plants ${ }^{[25]}$ 
Sampling was carried out at five SSI plants: plants EP1, EP2, EP+WEP, BF, and plant CF, which were sampled during on May 12-14, 2010, November 19-21, 2012, May 26-28, 2010, July 11-13, 2012, and November 17-19, 2010, respectively. In all plants, samples were collected from the dust collector and stack inlets to evaluate the proportion removed by the air pollution control devices (APCDs). Fig. 1 shows the sampling points. Dust samples in SSI flue gas were collected isokinetically in nine particle size fractions (from submicron to approximately $10 \mu \mathrm{m}$ ) using Andersen stack samplers (AS-500, Tokyo Dylec, Japan) inserted into the flue gas ducts of five SSI plants. The sampling methods were based on Japanese Industrial Standards (JIS) Z8808 and K0302. ${ }^{[26,27]}$ The representative particle size at each stage of the cascade impactor is defined as the aerodynamic particle size at which $50 \%$ separation is achieved and was obtained using the following equation:

$D_{p 50 n}=-1.26 \times \lambda+\sqrt{1.58 \times \lambda^{2}+\frac{1.08 \times \pi \times N \times \Psi_{50} \times D_{c n}^{\mathrm{a}} \times\left(172+0.4 \times \theta_{s}\right) \times 10^{-1}}{4 \times q_{s}}}$

$D_{p 50 n}: 50 \%$ separation particle size at the $n^{\text {th }}$ stage $(\mu \mathrm{m})$

$N$ : number of jet nozzles at the $n^{\text {th }}$ stage

$D_{c n}$ : bore of the jet nozzles at the $n^{\text {th }}$ stage (mm)

$\Psi_{50}$ : inertia parameter for $50 \%$ separation by particle size

$\theta_{s}$ : flue gas temperature $\left({ }^{\circ} \mathrm{C}\right)$

$q_{s}$ : suction flow rate at the suction nozzle ( $\left.\mathrm{L} / \mathrm{min}\right)$

$\lambda$ : mean free path of a gas molecule $(\mu \mathrm{m})$

In this formula, the mean free path of a gas molecule $(\lambda)$ was obtained using equation (2).

$\lambda=2.10 \times 10^{-5} \times\left(172+0.4 \times \theta_{s}\right) \times \sqrt{\left(273+\theta_{s}\right)}$

A period of at least 5 min was required for sample collection at the dust collector inlets and $44 \mathrm{~h}$ at the stack inlets. Two impingers (one without solution and the other with $5 \% \mathrm{H}_{2} \mathrm{O}_{2}$ ) were placed behind the samplers to remove moisture and to absorb any gaseous substances in flue gas that had removed dust. Samplings was carried out under stable conditions. Table 1 and FIG. 2. summarize the sampling conditions and sampling design, respectively.

TABLE 2 Sampling conditions

FIG. 2. Design for sampling dust in flue gas

\section{Analysis}

The quartz filters used for sampling were heated at $250^{\circ} \mathrm{C}$ for $2 \mathrm{~h}$ and cooled to room temperature before sampling to remove volatile substances. Before and after sampling, each filter was dried and weighed in a 
clean room kept at $21.5^{\circ} \mathrm{C}$ (upper: $23^{\circ} \mathrm{C}$, lower: $20^{\circ} \mathrm{C}$ ) and $35 \%$ relative humidity (upper: $40 \%$, lower: 30\%), using microbalances (M5P-F, Sartorius, USA, or XP26, METTLER TOLEDO, USA) at a sensitivity of $1 \mu \mathrm{g}$. To determine the PM2.5 fraction exactly, the fraction up to a diameter of $2.5 \mu \mathrm{m}$ was divided linearly according to the upper and lower diameters defining the fraction.

\section{RESULTS AND DISCUSSION}

\section{Dust concentration}

Figure 3a shows mass distribution versus aerodynamic diameter at the inlet of the stack. In particular, more than $90 \%$ of dust collected from the stacks of EP1 and EP2 consisted of particles under $3 \mu \mathrm{m}$. Although 55-90\% of the stack dusts from WEP and CF also tended to consist of particles under $3 \mu \mathrm{m}$, some stack dust fractions from WEP and CF and most from BF were collected in only small amounts, and their weight was negligible. Figure $3 b$ shows mass distribution versus aerodynamic diameter at the inlet of the dust collector. Of the dusts collected from the collectors of EP1, EP2, and WEP, 80-90\% consisted of particles under $10 \mu \mathrm{m}$. In contrast, $40-70 \%$ of dusts collected from the dust collectors of BF and CF tended to consist of particles over $5 \mu \mathrm{m}$. Pretreatment of flue gases with a cyclone in some plants can account for this differences in size distribution at the dust collector. ${ }^{[18]}$

FIG. 3. Mass distribution of dust. (a) at inlet of stack, (b) at inlet of dust collector. Dp: aerodynamic diameter.

The total dust and PM2.5 concentrations at the dust collector and stack inlets at each SSI plant are shown in Figure 4. The total dust and PM2.5 concentrations were $<0.32-5,000 \pm 670$ and $<0.14-4,800 \pm 730$ $\mu \mathrm{g} / \mathrm{Nm}^{3}$ (mean \pm mean deviation), respectively, in the flue gas in the stacks. Ehrlich et al. and Tirler et al. reported that the PM2.5 concentrations in German and Italian waste incineration plants were 752 and 32.9 $\mu \mathrm{g} / \mathrm{Nm}^{3}$, respectively ${ }^{[10,12]}$. Our results for plants WEP, BF, and CF were within the same or smaller range, while the results for plants EP1 and EP2 were considerably larger. More than 55\% of total dust in the stack consisted of PM2.5. This result is similar to those reported by Ehrlich et al. ${ }^{[10]}$ and Bounanno et al.. ${ }^{[11]}$ The PM2.5 concentration at the stack inlet of plant BF was less than the annual average Japanese environmental standard $\left(15 \mu \mathrm{g} / \mathrm{m}^{3}\right)$. Plant BF operated a state-of-the-art APCD, and the PM2.5 concentrations remained less than $0.14 \mu \mathrm{g} / \mathrm{Nm}^{3}$. In contrast, the PM2.5 and total dust levels at plants EP1 and EP2 were considerably higher than those at the other plants. Similar results were reported previously for municipal solid waste incinerators ${ }^{[13,14]}$. The respective total dust and PM2.5 concentrations in the dust collector inlet were $1.5 \pm$ 0.5 and $0.43 \pm 0.13 \mathrm{~g} / \mathrm{Nm}^{3}$ in plant EP1, $0.45 \pm 0.8$ and $0.32 \pm 0.7 \mathrm{~g} / \mathrm{Nm}^{3}$ in plant EP2, $4.4 \pm 0.3$ and $1.9 \pm$ $0.1 \mathrm{~g} / \mathrm{Nm}^{3}$ in plant $\mathrm{EP}+\mathrm{WEP}, 5.6 \pm 0.3$ and $0.51 \pm 0.09 \mathrm{~g} / \mathrm{Nm}^{3}$ in plant $\mathrm{BF}$, and $3.9 \pm 1.0$ and $0.86 \pm 0.09$ $\mathrm{g} / \mathrm{Nm}^{3}$ in plant CF. The BF, WEP, and CF removed PM2.5 efficiently, but not the EP.

FIG. 4. Total dust and PM2.5 concentrations in the dust collector inlet 
and the stack inlets at SSI plants ; error bar is mean deviation.

\section{Removal of PM2.5 by APCD}

The removal efficiency of PM2.5 and dust from the plants was investigated to determine the relationship of PM2.5 and the dust concentration in the stack inlet for different dust collectors, where the removal efficiency was calculated as follows:

$$
\eta=\left(1-\frac{C_{o N} Q_{o N}}{C_{i N} Q_{i N}}\right) \times 100
$$

$\eta$ : removal efficiency (\%)

$163 C_{i N}$ : dust or PM2.5 concentrations at the dust collector inlet of each plant $\left(\mathrm{g} / \mathrm{Nm}^{3}\right)$

$C_{o N}$ : dust or PM2.5 concentrations at the stack inlet of each plant $\left(\mathrm{g} / \mathrm{Nm}^{3}\right)$

$165 Q_{i N}$ : flow rate of flue gas at the dust collector inlet of each plant $\left(\mathrm{Nm}^{3} / \mathrm{h}\right)$

$Q_{o N}$ : flow rate of flue gas at the stack inlet of each plant $\left(\mathrm{Nm}^{3} / \mathrm{h}\right)$

The results are shown in Table 3. Plants EP+WEP, BF, and CF removed more than 99.99\% of the PM2.5 and total dust, demonstrating that those dust collectors are effective for particle emission control. Most importantly, BF was the best dust collector in terms of both the dust concentration in the stack inlet and removal efficiency. The EP at plants EP1 and EP2 were the least efficient collectors. These findings are similar to the results of studies of municipal solid waste incinerators ${ }^{[13,14]}$, in which the PM2.5 removal efficiency of BF was higher than that of EP. The European Environment Agency (EEA) reported that the PM2.5 removal efficiency was 77-98\% for industrial waste incineration, including hazardous waste and sewage sludge with some APCDs. ${ }^{[28]}$ In 1996, a U.S. Environmental Protection Agency (US EPA) report ${ }^{[29]}$ suggested that advances in incineration and APCD technology have improved removal efficiency. Replacing dry EP with BF would improve the PM2.5 removal in SSIs.

Table 3 Removal efficiency of total dust and PM2.5 by APCDs

\section{Calculating the PM2.5 Emission Factor from SSIs}

To evaluate PM2.5 emissions from SSIs in Japan, we calculated the emission factor for PM2.5 from our results although there were insufficient samples taken at each SSI plant. We surveyed the number and incineration capacity of SSIs with each type of dust collector, and calculated the PM2.5 emissions. These methods are described in detail below. Dust removal efficiency is generally known to be higher in WEP, BF, and CF than in EP. ${ }^{[18]}$ Temperature resistance differes between BF and CF. Because these dust collectors have different characteristics, we calculated the emission factor for each dust collector separately (EP, WEP, BF, and CF). The factor for EP was the average of those calculated for plants EP1 and EP2. In this study, the emission factor is defined as the weight of PM2.5 per ton of sewage sludge incineration capacity. The emission factor is defined by the following equation: 
192

$$
E f=\frac{24 \times Q \times A}{10^{6} \times B}
$$

194 Ef: emission factor, weight of PM2.5 per ton of the incineration capacity (g/ton-sludge cake)

195 Q: flow rate of flue gas at the stack inlet in the plant ( $\mathrm{Nm}^{3} /$ hour)

196 A: concentration of PM2.5 at the stack inlet $\left(\mu \mathrm{g} / \mathrm{Nm}^{3}\right)$

197

$B$ : incineration capacity of the plant (ton-sludge cake/day)

198

The resulting emission factors are shown in Table 4. The PM2.5 emission factor for the SSI with EP was $8.7 \mathrm{~g} /$ ton-sludge cake, whereas those for wet EP, BF or CF were less than $0.26 \mathrm{~g} /$ ton-sludge cake and BF had the lowest value. The US EPA has set $0.18 \mathrm{~kg} / \mathrm{Mg}$-DS as the PM2.5 emission factor for a fluidised bed incinerator for SSI with a scrubber; this equals $180 \mathrm{~g} /$ ton-DS or approximately $36 \mathrm{~g} /$ ton-sludge cake based on an $80 \%$ water content. ${ }^{[30]}$ The EEA set $0.004 \mathrm{~kg} / \mathrm{Mg}$-waste (4 g/ton-waste) as the default PM2.5 emission factor for industrial waste incineration, including hazardous waste and sewage sludge. ${ }^{[28]}$ Although the units and materials burned in these other studies differed, the results were similar to the values set by the US EPA and EEA, and the values for WEP, BF, and CF were considerably smaller. Therefore, advances in technology could improve the removal efficiency.

Table 4 Emission factors of PM2.5

The results of the survey of the number and incineration capacity of SSI plants with each type of dust 85 plants responded. The total incineration capacity was 9,950 ton/day, which is $48 \%$ of the total number of plants and 39.3\% of total plant capacity, for all of the SSI plants in Japan. ${ }^{[31]}$

Table 5 Results of survey on SSI plants and calculated PM2.5 emission values

The PM2.5 emissions are defined by the following equation:

$$
E=\sum_{i=1}^{4} \frac{E f \times C}{10^{6}} \times \frac{X i}{100}
$$

E: annual emissions of PM2.5 from SSIs (ton/year) 
227

228

229

230

231

232

233

234

235

236

237

238

239

240

241

242

243

244

245

246

247

248

249

250

251

252

253

254

255

256

257

258

259

260

261

262

263

Xi: relative incineration capacity of SSI plants with each type of dust collector (\%)

The emission results are shown in Table 6. These calculations are outlined in detail below. There were 92 plants with no available information on dust collector type. We assumed that all of these 92 plants were equipped with EP, WEP, BF, or CF, representing cases I, II, III, and IV, respectively (in Table 5). The amount of sewage sludge burnt annually in SSIs is 1.5 million tons-DS/year, or $68 \%$ of the 2.2 million tons-DS/year produced annually; these amounts are on a dry weight basis. ${ }^{[15]} \mathrm{It}$ is possible that the PM2.5 emissions are underestimated. The total estimated emissions of PM2.5 from SSIs were 0.96-8.9 tons/year, of which more than $75 \%$ was from SSIs equipped with EP. Sugiyama et al. estimated that the total PM2.5 emissions in 2000 in Japan were 252 kton, of which 49\% was from mobile emission sources. ${ }^{[32]}$ Kannari et al. estimated that anthropogenic PM2.5 emissions in 2000 in Japan equalled $147 \mathrm{Gg}$, of which $12 \%$ was due to waste incineration and field burning. ${ }^{[33]}$ The PM2.5 emissions from SSIs in our study was less than $0.0035 \%$ of the total estimated by Sugiyama et al. and less than $0.006 \%$ that of Kannari et al., so the contribution of SSIs to the total PM2.5 emissions is negligible. The emission results in our study could be underestimated because of the difference in units between $\mathrm{Ef}$ (g/ton-sludge cake) and C (ton-DS/year), the difference in the real amount of burnt sewage sludge, and incineration capacity. Because most of the PM2.5 emissions might originate from plants with EP, replacing dry EP with BF could significantly reduce the PM2.5 emissions from SSIs.

Table 6 Calculated PM2.5 emission values

\section{CONCLUSIONS}

This study measured the concentrations and removal efficiency of PM2.5 and total dust in flue gas from five SSI plants. The average PM2.5 concentration in the stack inlet of the plant with BF was lower than the Japanese environmental standard for ambient air ( $15 \mu \mathrm{g} / \mathrm{m}^{3}$ annually). In the plants with WEP or CF, the PM2.5 concentrations in the stack inlet were also close to the environmental standard ( $35 \mu \mathrm{g} / \mathrm{m}^{3}$ daily). The removal efficiencies of the plants with these dust collectors exceeded 99.99\%. The emission of PM2.5 as primary particles from these plants was very low. By contrast, the plants with EP not only had the highest PM2.5 concentrations in the stack inlets but also the lowest PM2.5 removal. The PM2.5 emission factor for SSIs using EP was $8.7 \mathrm{~g}$ /ton-sludge cake, whereas that with wet EP, BF, or CF was less than 0.26 g/ton-sludge cake. The total estimated emission of PM2.5 from SSI in Japan was 0.96-8.9 ton/year, which was less than $0.0035 \%$ of the total PM2.5 emissions and $0.006 \%$ of the anthropogenic PM2.5 emissions estimated for Japan for 2000, although these emissions could underestimates. Since the SSIs with dry EP contributed 75-99\% to the total emissions, replacing a dry EP with BF would significantly reduce the PM2.5 from SSIs. 
The results suggest that PM2.5 emissions as primary particles from some SSI plants were very low. Future work should determine the contribution of secondary particles from gaseous substances such as $\mathrm{SO}_{2}$, $\mathrm{HCl}$, and $\mathrm{NO}$ in ambient air.

\section{REFERENCES}

1. Cao, C.; Jiang, W.; Wang, B.; Fang, J.; Lang, J.; Tian, G.; Jiang, J.; F. Zhu, T. F. Inhalable Microorganisms in Beijing's PM2.5 and PM10 Pollutants during a Severe Smog Event. Environmental Science and Technology 2014, 48 (3), 1499-1507.

2. Cheng Z.; Jiang J.; Fajardo O.; Wang S.; Hao J. Characteristics and health impacts of particulate matter pollution in China (2001-2011). Atmospheric Environment 2013, 65 (0), 186-194

3. Dockery, D.W.; Pope, C.A.; Xu, X.; Spengler, J.D.; Ware, J.H.; Fay, M.E.; Ferris, B.G.; Speizer, F.E. An association between air pollution and mortality in six U.S. cities. New England Journal of Medicine 1993, 329, 1753-1759.

4. Pope, C. A.; Thun, M. J.; Namboodiri, M. M.; Dockery, D. W.; Evans, J. S.; Speizer, F. E.; Heath, C. W. Particulate air pollution as a predictor of mortality in a prospective study of U.S. adults. American Journal of Respiratory and Critical Care Medicine 1995, 151, 669- 674.

5. European Standard. Ambient air quality standard gravimetric measurement method for the determination of the PM2.5 mass fraction of suspended particulate matter; EN14907; 2005.

6. United States Environmental Protection Agency. 40 CFR, Parts53 and 58; 2006.

7. World Health Organization. WHO air quality guidelines for particulate matter, ozone, nitrogen dioxide and sulphur dioxide. Global update 2005, Summary of risk assessment, WHO Geneva, 2006.

8. Hänninen, O.; Knol, A. EBoDE-Report. Environmental Perspectives on Environmental Burden of Disease Estimates for Nine Stressors in Six European Countries. National Institute for Health and Welfare (THL), 2011.

9. International Agency for Research on Cancer. Outdoor air pollution a leading environmental cause of cancer death. http://www.iarc.fr/en/media-centre/iarcnews/pdf/pr221_E.pdf (accessed 29 July 2014)

10. Ehrlich, C.; Noll, G.; Kalkoff, W. D.; Baumbach, G.; Dreiseidler, A. PM10, PM2.5 and PM1.0Emissions from industrial plants-Results from measurement programmes in Germany. Atmospheric Environment 2007, 41, 6236-6254.

11. Buonanno, G.; Ficco, G.; Stabile, L. Size distribution and number concentration of particles at the stack of a municipal waste incinerator, Waste management 2009, 29, 749-755

12. Tirler W.; Angelucci G.; Bedin K.; Voto G.; Donegà M.; Minach L. Active sampling and analysis of dioxins and polyaromatic hydrocarbons bound to fine particles in the vicinity of a municipal solid waste incinerator. Organohalogen Compounds 2007, 69, 2268-2271.

13. Shiota, K.; Imai, G.; Takaoka, M.; Kimoto, S.; Matsui, Y.; Oshita, K.; Mizuno, T.; Morisawa, S. The effect of countermeasures for dioxin removal on the emission of fine particles from municipal solid waste incinerators. Journal of Japan Society for Atmospheric Environment 2011, 46, 224-232. (in Japanese)

14. Takaoka, M.; Shiota, K.; Imai, G.; Oshita, K.; Emission of particulate matter 2.5 (PM2.5) from 
303

304

305

306

307

308

309

310

311

312

313

314

315

316

317

318

319

320

321

322

323

324

325

326

327

328

329

330

331

332

333

334

335

336

337

338

339

340

341

municipal solid waste incinerators. In Proceedings of 7th i-CIPEC, Seoul, Korea, 2012; 156-162.

15. Japan Swage Works Association. Sewage Works in Japan 2008, Flow chart of the year-on-year treatment and utilization amount of sewage sludge in Japan; 2010. http://www.jswa.jp/dataroom/data.html (accessed 29 July 2014) (in Japanese)

16. Tazaki, M. Energy efficiency in sewage sludge incineration system, Kyoto University Doctoral Dissertation 2011. http://hdl.handle.net/2433/151996 (in Japanese)

17. Takaoka M.; Domoto S.; Oshita K.; Takeda N.; Morisawa S. Mercury emission from sewage sludge incineration in Japan. Journal of Material Cycles Waste Management 2012, 14, 113-119.

18. Vehlow, J. Air pollution control systems in WtE units: An overview. Waste Management 2014. in press. 19. Chen, G.; Yue, P. L.; Mujumdar, S. Sludge Dewatering and Drying. Drying Technology 2002, 20, 883916.

20. Oshita, K.; Takaoka, M.; Nakajima, Y.; Morisawa, S.; Kanda, H.; Makino, H.; Takeda, N. Sewage Sludge Dewatering Process Using Liquefied Dimethyl Ether as Solid Fuel. Drying Technology 2011, 29, 624-632.

21. Tazaki, M.; Tsuno, H.; Takaoka, M.; Shimizu, K. Modeling of Sludge Behavior in a Steam Dryer. Drying Technology 2011, 29, 1748-1757.

22. Peregrina, C.; Arlabosse, P.; Lecomte, D.; Rudolph, V. Heat and Mass Transfer During Fry-Drying of Sewage Sludge. Drying Technology 2006, 24(7), 797-818.

23. Ayol, A.; Durak, G. Fate and Effects of Fry-Drying Application on Municipal Dewatered Sludge. Drying Technology 2013, 31, 350-358.

24. Tuan, P-A.; Mika, S.; Pirjo, I. Sewage Sludge Electro-Dewatering Treatment-A Review. Drying Technology 2012, 30, 691-706.

25. Japan Sewage Works Association. Sewage Works in Japan 2011, Sludge Dewatering and Sludge Incineration in Japan; 2013. (in Japanese)

26. Japan Industrial Standard. Methods of measuring dust concentration in flue gas; JIS Z8808; 1995. (in Japanese)

27. Japan Industrial Standard. Measuring Method for Particle-size Distribution of Dusts in Flue Gas; JIS K0302; 1989. (in Japanese)

28. European Environment Agency. EMEP/EEA air pollutant emission inventory guidebook 2013, http://www.eea.europa.eu//publications/emep-eea-guidebook-2013 , 2013(accessed 25 March 2014)

29. United States Environmental Protection Agency. AP42, Fifth Edition, Volume1, Compilation of Air Pollutant Emission Factors Vol.1. Stationary, Point and Area Sources Report, 1996.

30. United States Environmental Protection Agency. AP42, Fifth Edition, Volume I, Chapter 2.2 Sewage Sludge Incineration, http://www.epa.gov/ttnchie1/ap42/ch02/index.html, 1994. (accessed 29 July 2014)

31. Japan Sewage Works Association. Japan Sewage Statistics in 2008; 2010. (in Japanese)

32. Sugiyama,T.; Nansai, K.; Tohno, S.; Yamamoto, K. Compilation and application of a primary PM2.5 emissions inventory with high sectoral resolution in Japan. Atmospheric Environment 2009, 43, 759-768. 33. Kannari, A.; Tonooka, Y.; Baba, T.; Murano, K. Development of multiple-species $1 \mathrm{~km} 1$ km resolution hourly basis emissions inventory for Japan. Atmospheric Environment 2007, 41, 3428-3439. 
$343 \quad$ Figure and Table captions

344

345 FIG. 1. Plant flow and sampling points

346 FIG. 2. Design for sampling dust in flue gas

347 FIG. 3. Mass distribution of dust. (a) at inlet of stack, (b) at inlet of dust collector. Dp: aerodynamic 348 diameter.

349 FIG. 4. Total dust and PM2.5 concentrations in the dust collector inlet and the stack inlets at SSI plants;

350 error bar is mean deviation.

351

352 TABLE 1 Technical data for five SSI plants

353 TABLE 2 Sampling conditions

354 TABLE 3 Removal efficiency of total dust and PM2.5 by APCDs

355 TABLE 4 Emission factors of PM2.5

356 TABLE 5 Result of survey on SSI plants and calculated PM2.5 emission values; caseI-IV are assumed 357 cases that there were 92 plants with no available information on dust collector type. In case I, II, III, and 358 IV, all of the 92 plants are assumed to be equipped with EP, WEP, BF, or CF, respectively

359 TABLE 6 Calculated PM2.5 emission values; caseI-IV are assumed cases that there were 92 plants with 360 no available information on dust collector type. In case I, II, III, and IV all of the 92 plants are assumed to 361 be equipped with EP, WEP, BF, or CF, respectively 


\section{Plant EP1}

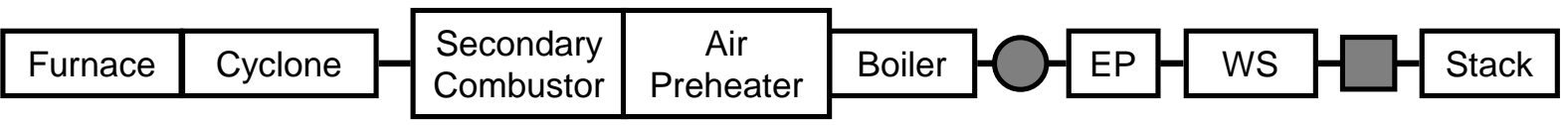

\section{Plant EP2}

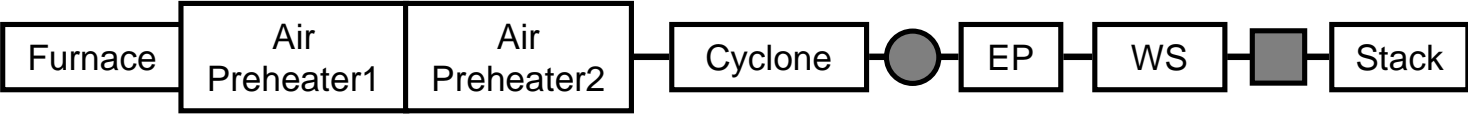

\section{Plant EP + WEP}

\begin{tabular}{|c|c|c|c|c|c|c|c|}
\hline Furnace & Air \\
Preheater & Boiler & Cyclone & SCR
\end{tabular}

\section{Plant BF}

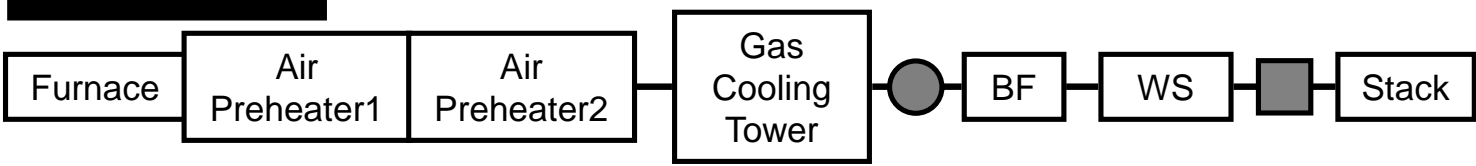

\section{Plant CF}

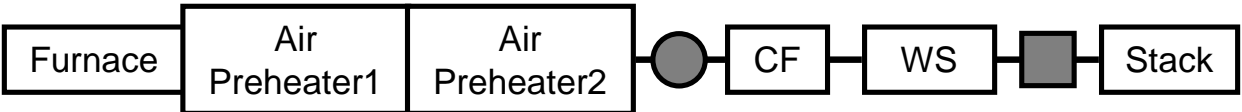

EP: Electrostatic Precipitator, WS: Wet Scrubber, WEP: Wet EP, BF: Bag Filter, CF: Ceramic Filter

: Sampling Place at Inlet of Dust Collectors,

FIG. 1. Plant flow and sampling points 
368

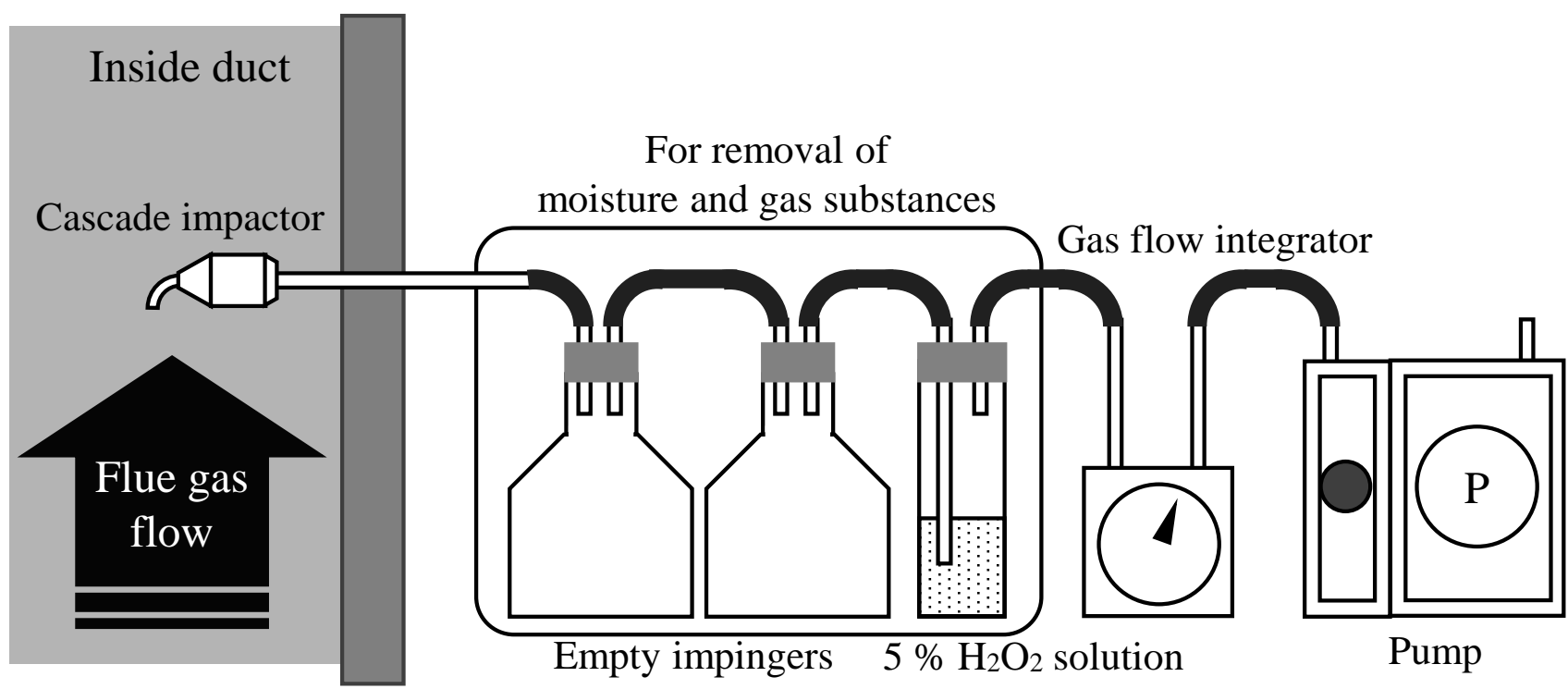

FIG. 2. Design for sampling dust in flue gas 
372
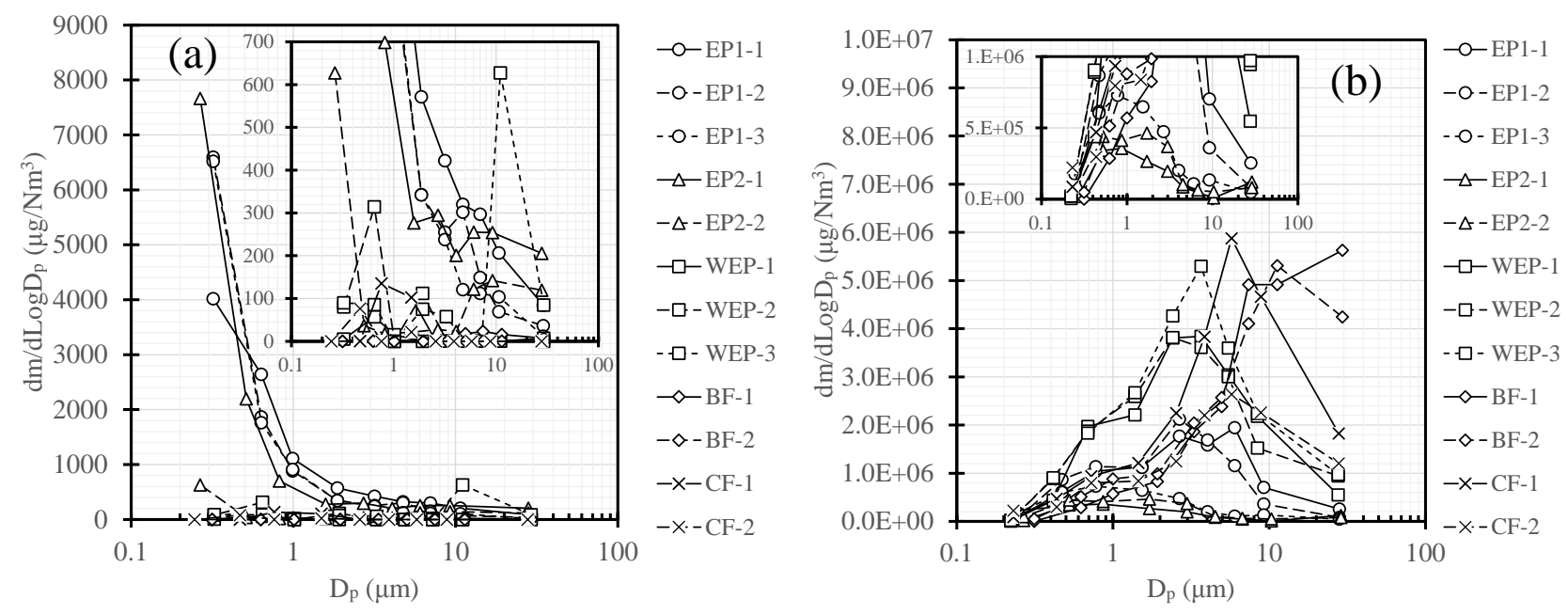

FIG. 3. Mass distribution of dust. (a) at inlet of stack, (b) at inlet of dust collector. $\mathrm{D}_{\mathrm{p}}$ : aerodynamic 375 diameter.

376 
377

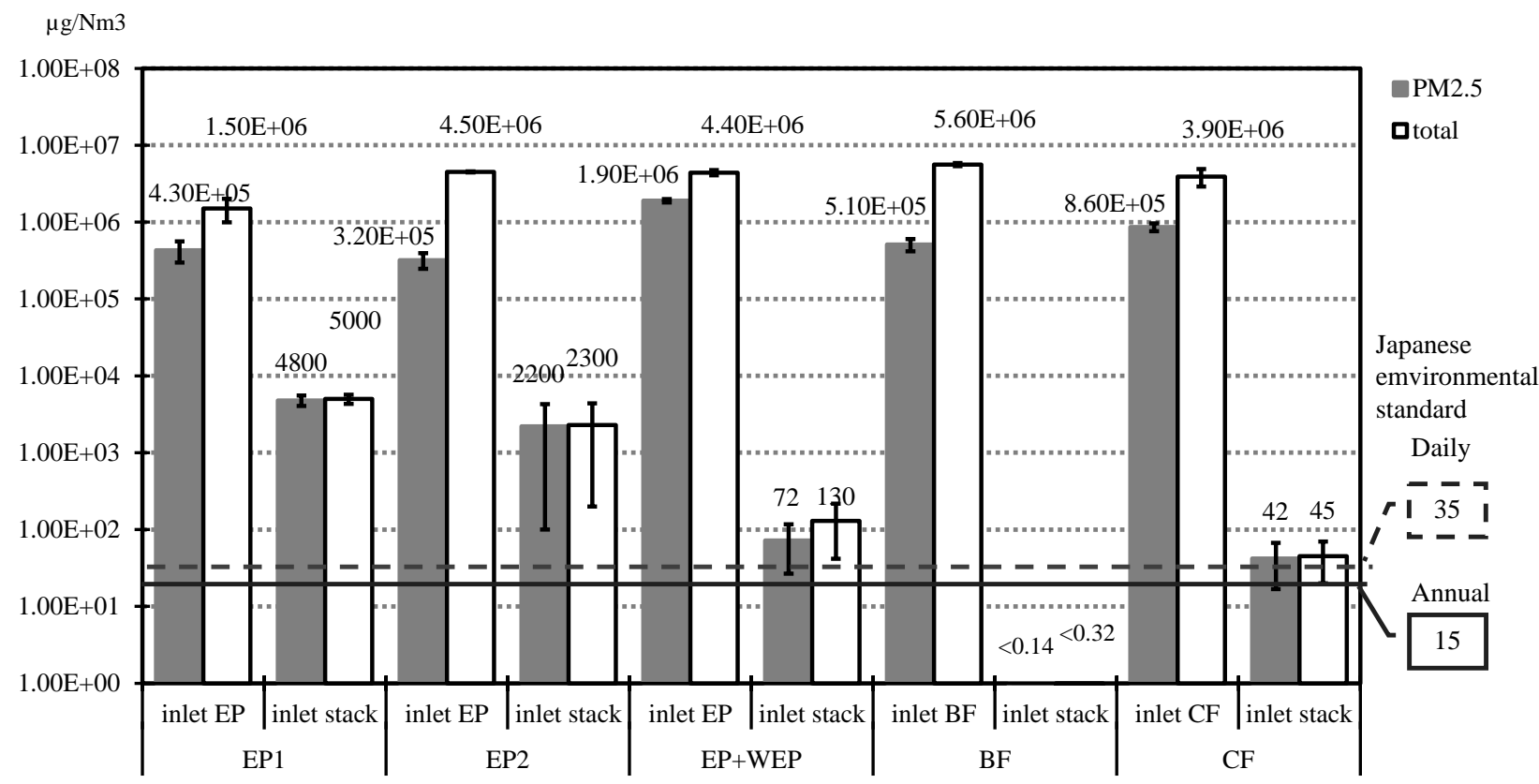

FIG. 4. Total dust and PM2.5 concentrations in the dust collector inlet and the stack inlets at SSI plants; error bar is mean deviation. 
TABLE 1

385

Technical data for five SSI plants

386

\begin{tabular}{|c|c|c|c|c|c|c|}
\hline \multirow{2}{*}{\multicolumn{2}{|c|}{$\begin{array}{c}\text { Plant } \\
\text { Parameters }\end{array}$}} & EP1 & EP2 & $\mathrm{EP}+\mathrm{WEP}$ & $\mathrm{BF}$ & $\mathrm{CF}$ \\
\hline & & & & & & \\
\hline \multicolumn{2}{|c|}{ Sludge incineration capacity (ton-sludge cake/day) } & 72 & 65 & 130 & 200 & 150 \\
\hline \multicolumn{2}{|c|}{ Incinerator } & Fluidized bed & Fluidized bed & Fluidized bed & Fluidized bed & Fluidized bed \\
\hline \multicolumn{2}{|c|}{ Annual mean of combustion temperature $\left({ }^{\circ} \mathrm{C}\right)$} & 850 & 820 & 850 & 854 & 850 \\
\hline \multicolumn{2}{|c|}{ Coagulant } & polymer & polymer & polymer & polymer & polymer \\
\hline \multicolumn{2}{|c|}{ Sludge dewatering } & Belt filter press & Belt filter press & Belt filter press & Centrifuge & $\begin{array}{l}\text { Screw press } \\
\text { Indirect heating }\end{array}$ \\
\hline \multicolumn{2}{|c|}{ Annual amount of sludge cake incineration (ton/year) } & 14,300 & 14,700 & $54,200^{(a)}$ & $147,000^{(\mathrm{a})}$ & $55,800^{(\mathrm{a})}$ \\
\hline \multirow[t]{3}{*}{ Sludge cake } & Water content (\%wet basis) & 84 & 74.6 & 76.8 & 80.6 & 77.8 \\
\hline & Organic content (\%dry basis) & 70.6 & 86 & 80.5 & 81.8 & 78 \\
\hline & (year) & 798 & 658 & $4100^{(a)}$ & $8100^{(a)}$ & $2680^{(\mathrm{a})}$ \\
\hline \multicolumn{2}{|c|}{ Reagent consumption in flue gas treatment } & $\begin{array}{c}\text { Sodium hydroxide } \\
\text { solution } \\
\text { at wet scrubber }\end{array}$ & $\begin{array}{c}\text { Sodium hydroxide } \\
\text { solution } \\
\text { at wet scrubber }\end{array}$ & $\begin{array}{c}\text { Sodium hydroxide } \\
\text { solution } \\
\text { at wet scrubber }\end{array}$ & $\begin{array}{c}\text { Sodium hydroxide } \\
\text { solution } \\
\text { at wet scrubber }\end{array}$ & $\begin{array}{c}\text { Sodium hydroxide } \\
\text { solution } \\
\text { at wet scrubber }\end{array}$ \\
\hline
\end{tabular}


389

390

\begin{tabular}{|c|c|c|c|c|c|c|c|c|c|c|c|}
\hline \multirow{2}{*}{$\begin{array}{c}\text { Plant } \\
\text { Sampling date } \\
\text { (year/month/day) } \\
\text { Parameters }\end{array}$} & & \multicolumn{2}{|c|}{ EP1 } & \multicolumn{2}{|c|}{ EP2 } & \multicolumn{2}{|c|}{ EP+WEP } & \multicolumn{2}{|c|}{$\mathrm{BF}$} & \multicolumn{2}{|c|}{$\mathrm{CF}$} \\
\hline & & $2010 / 4 / 12$ & 2010/4/12-14 & 2012/11/19 & 2012/11/19-21 & $2010 / 5 / 26$ & 2010/5/26-28 & $2012 / 7 / 11$ & 2012/7/11-13 & 2010/11/17 & 2010/11/17-19 \\
\hline \multicolumn{2}{|l|}{ Sampling points } & Inlet of EP & Inlet of stack & Inlet of EP & Inlet of stack & Inlet of EP & Inlet of stack & Inlet of $\mathrm{BF}$ & Inlet of stack & Inlet of CF & Inlet of stack \\
\hline \multicolumn{2}{|l|}{ Flue gas flow rate $(\mathrm{m} / \mathrm{s})$} & 16.5 & 2.8-3.1 & 14.3 & 4.8 & 20.3 & 18.1-19.5 & 22.5 & 22.3-23.6 & 18.9 & $15.3-16.7$ \\
\hline \multicolumn{2}{|l|}{$\left(\mathrm{Nm}^{3} /\right.$ hour $)$} & 3,130 & $4,320-4,870$ & 4,620 & $12,400-12,700$ & 9,640 & $18,500-20,000$ & 17,300 & $34,600-37,100$ & 12,800 & $24,700-26,500$ \\
\hline \multicolumn{2}{|l|}{ Flue gas temperature $\left({ }^{\circ} \mathrm{C}\right)$} & 276 & 30-35 & 338 & 134 & 296 & $69-80$ & 202 & $198-215$ & 316 & $186-202$ \\
\hline \multicolumn{2}{|l|}{ Relative humidity (\%) } & 22 & $3.2-3.4$ & 27.4 & 4.3 & 43.3 & $4.4-7.0$ & 45.9 & $1.6-3.6$ & 35.5 & 2.5 \\
\hline \multicolumn{2}{|l|}{$\mathrm{O}_{2}(\%)$} & 10.8 & 12.3 & 10.2 & $15.8-16.1$ & 6 & $10.5-15.1$ & 6.7 & 15.3 & 9.2 & $15.1-15.8$ \\
\hline \multicolumn{2}{|l|}{$\mathrm{CO}_{2}(\%)$} & 9.1 & 7.9 & 9.1 & $3.9-4.1$ & 14.3 & $5.5-10.0$ & 11.2 & $3.9-4.1$ & 9.1 & $3.5-5.1$ \\
\hline \multicolumn{2}{|l|}{$\mathrm{N}_{2}(\%)$} & 80.1 & 79.8 & 80.7 & $80.0-80.1$ & 79.7 & 79.4-79.5 & 82.1 & $80.6-80.8$ & 81.7 & $79.8-80.7$ \\
\hline \multicolumn{2}{|l|}{ Diameter of suction (mm) } & 6 & 10 & 6 & 10 & 6 & 4 & 4 & 4 & 6 & 4 \\
\hline \multicolumn{2}{|l|}{ Suction flow rate $(\mathrm{m} / \mathrm{s})$} & 10.4 & 11.6 & 9.2 & 13.4 & 8.9 & 11 & 5.4 & 10 & 6.1 & 13.5 \\
\hline \multirow[t]{2}{*}{ Suction time } & & $6 \mathrm{~min}$ & $44 \mathrm{hrs}$ & $5 \mathrm{~min}$ & $48 \mathrm{hrs}$ & $5 \mathrm{~min}$ & $44 \mathrm{hrs}$ & $5 \mathrm{~min}$ & $47 \mathrm{hrs}$ & $5 \mathrm{~min}$ & $48 \mathrm{hrs}$ \\
\hline & 1 & 0.0626 & 30.8 & 0.0367 & 38.9 & 0.0443 & 27 & 0.027 & 28.4 & 0.0305 & 38.8 \\
\hline \multirow[t]{2}{*}{ Suction gas volume $\left(\mathrm{Nm}^{3}\right)$} & 2 & 0.0626 & 30.6 & 0.0367 & 37.7 & 0.0443 & 29.6 & 0.027 & 28.5 & 0.0305 & 38.9 \\
\hline & 3 & 0.0627 & 30.6 & - & - & 0.0443 & 29.9 & - & - & 0.0305 & - \\
\hline
\end{tabular}

391

EP: Electrostatic Precipitator , WEP: Wet Electrostatic Precipitator , BF: Bag Filter, CF: Ceramic Filter

TABLE 2

Sampling conditions

392 
393

394

395

396

397
TABLE 3

Removal efficiency of total dust and PM2.5 by APCDs

\begin{tabular}{cccccc}
\hline \multicolumn{5}{c}{ Removal efficiency (\%) } \\
Plant & EP1 & EP2 & EP+WEP & BF & CF \\
\hline PM2.5 & 98.75 & 98.75 & $99.99<$ & $99.99<$ & 99.99 \\
Total & 99.63 & 99.91 & $99.99<$ & $99.99<$ & $99.99<$ \\
\hline
\end{tabular}

\section{7}


TABLE 4

399

Emission factors of PM2.5

\begin{tabular}{|c|c|c|c|c|}
\hline Plant & EP1 & EP+WEP & $\mathrm{BF}$ & $\mathrm{CF}$ \\
\hline APCD & Cyclone, EP, WS & $\begin{array}{l}\text { Cyclone, EP, } \\
\text { WS, WEP }\end{array}$ & BF, WS & CF, WS \\
\hline $\begin{array}{c}\text { Emission factor of } \\
\text { PM2.5 } \\
\text { (g/ton-sludge cake) }\end{array}$ & 8.7 & 0.26 & $<5.9$ E-7 & 0.17 \\
\hline
\end{tabular}

APCD: Air Pollution Control Device, EP: Electrostatic Precipitator

WEP: Wet Electrostatic Precipitator , BF: Bag Filter, CF: Ceramic Filter

400

WS: Wet Scrubber

401

402 
403

404

405

406

407

408

409

\section{TABLE 5}

Result of survey on SSI plants and calculated PM2.5 emission value; caseI-IV are assumed cases because there were 92 plants with no available information on dust collector type. In case I, II, III, and IV all of the 92 plants are assumed to be equipped with EP, WEP, BF, or CF, respectively

\begin{tabular}{|c|c|c|c|c|c|c|c|}
\hline \multirow{2}{*}{ Dust collector type } & \multirow{2}{*}{ Number of plants } & \multirow{2}{*}{$\begin{array}{c}\text { Sum of incineration capacity } \\
\text { (ton-sludge cake/day) }\end{array}$} & \multicolumn{4}{|c|}{ Ratio of incineration capacity (\%) } & \multirow{2}{*}{$\begin{array}{c}\text { Use of emission factor } \\
\text { (g/ton-sludge cake) }\end{array}$} \\
\hline & & & Case I & Case II & Case III & Case IV & \\
\hline Cyclone, EP & 24 & 1750 & 67.6 & 6.9 & 6.9 & 6.9 & 8.7 \\
\hline Cyclone, EP, WEP & 14 & 2200 & 8.7 & 69.4 & 8.7 & 8.7 & 0.26 \\
\hline $\mathrm{BF}$ & 34 & 3500 & 13.8 & 13.8 & 74.5 & 13.8 & $<5.9 \mathrm{E}-7$ \\
\hline $\mathrm{CF}$ & 13 & 2500 & 9.9 & 9.9 & 9.9 & 70.6 & 0.17 \\
\hline No information & 92 & 15383 & all of EP & all of EP+WEP & all of $\mathrm{BF}$ & all of CF & - \\
\hline Whole of Japan & 177 & 25333 & 100 & 100 & 100 & 100 & - \\
\hline
\end{tabular}

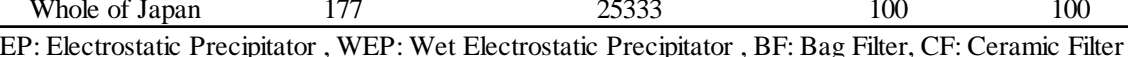


410

411

412

413

414

415

416

417

\section{TABLE 6}

Calculated PM2.5 emission values; caseI-IV are assumed cases because there were 92 plants with no available information on dust collector type. In case I, II, III, and IV all of the 92 plants are assumed to be equipped with $\mathrm{EP}, \mathrm{WEP}, \mathrm{BF}$, or $\mathrm{CF}$, respectively

\begin{tabular}{cccccc}
\hline Dust collector type & Case I & Case II & $\begin{array}{c}\text { Case III Case IV } \\
\text { (ton/year) }\end{array}$ & Emission of PM2.5 \\
\hline Cyclone, EP & 8.8 & 0.90 & 0.90 & 0.90 & $0.90-8.8$ \\
Cyclone, EP, WEP & 0.034 & 0.27 & 0.034 & 0.034 & $0.034-0.27$ \\
BF & $1.2 \mathrm{E}-7$ & $1.2 \mathrm{E}-7$ & $6.7 \mathrm{E}-7$ & $1.2 \mathrm{E}-7$ & $<1.2 \mathrm{E}-7-6.7 \mathrm{E}-7$ \\
CF & 0.025 & 0.025 & 0.025 & 0.18 & $0.025-0.18$ \\
Sum & 8.9 & 1.19 & 0.96 & 1.11 & $0.96-8.9$ \\
\hline
\end{tabular}

EP: Electrostatic Precipitator, WEP: Wet Electrostatic Precipitator

BF: Bag Filter, CF: Ceramic Filter 
418 The English in this document has been checked by at least two professional editors, both native 419 speakers of English. For a certificate, please see:

420

421 http://www.textcheck.com/certificate/gDWW2X

422

423

424 